\title{
Choice of postpartum contraception and its socio-demographic and cultural determinants
}

\author{
Vidyadhar B. Bangal*, Sunil Thitame, K. V. Somasundaram
}

Centre for Social Medicine, Pravara Institute of Medical Sciences (Deemed to be University) Loni, Ahmednagar, Maharashtra, India

Received: 23 April 2020

Accepted: 29 May 2020

\section{*Correspondence:}

Dr. Vidyadhar B. Bangal,

E-mail: vbb217@rediffmail.com

Copyright: ( $)$ the author(s), publisher and licensee Medip Academy. This is an open-access article distributed under the terms of the Creative Commons Attribution Non-Commercial License, which permits unrestricted non-commercial use, distribution, and reproduction in any medium, provided the original work is properly cited.

\begin{abstract}
Background: Postpartum contraception is essential for avoidance of unwanted pregnancy and for adequate spacing between two pregnancies. There are many socio demographic and cultural factors that influence the choice of contraception in rural community in India. Third trimester of pregnancy is ideal time for counselling the women regarding breast feeding and contraception. The objective of the present study was to find out the choice of postpartum contraception among antenatal women and the socio demographic and cultural determinants that influence this choice.

Methods: Six hundred pregnant women were interviewed regarding their choice of postpartum contraception during their antenatal visit in third trimester of pregnancy, using a pre-validated and pre-tested brief questionnaire. The choices were compiled and analysed to draw conclusions.

Results: Postpartum sterilization was choice of $30 \%$ of multiparous women. Primi-parous women either opted for barrier contraception like condom $(10 \%)$, intrauterine contraception $(9 \%)$ or oral steroidal pills $(8 \%)$. The progesterone injectable contraceptives and centchroman each were chosen by $2 \%$ respondents. There was strong influence of education, parity, sex of the living children on the choice of contraception. It was observed that $40 \%$ of women did not want to use hormonal pills and intrauterine contraceptives due to strong age old misbelieves associated with them.

Conclusions: Women in rural area prefer permanent method of contraception in the form of tubectomy operation after having desired number of children. There is insufficient spacing between pregnancies due to either non-use of contraception or inconsistent use of temporary method of contraception. More than $50 \%$ women are dependent on the husband regarding the choice and practice of contraception. The level of education of woman, age at marriage, socio economic class, desired sex combination of children are strong determinants of choice of contraception.
\end{abstract}

Keywords: Family planning, Injectable progesterone, Postpartum contraception, Postpartum intra uterine contraceptive device, Tubectomy

\section{INTRODUCTION}

The World Health Organisation recommends that women delay conception for at least two years after they give birth. Delaying a second pregnancy for at least two years after childbirth is known as birth spacing. It has important health benefits, both for pregnant women and the babies they bear. It provides time for the woman's body to recuperate from the additional demands of pregnancy and childbirth. Scientists have found this also benefits the health of her growing foetus during subsequent pregnancy and the new-born baby after childbirth. ${ }^{1,2}$ There are many considerations a woman must make about contraceptive use after childbirth. In particular, the woman must decide which contraceptive method to use and when to start using contraception. ${ }^{3}$ A number of 
factors will influence these choices. The factors which are most important in determining the best contraceptive method to use and the appropriate time to begin using it are: whether or not the woman is breastfeeding; and if breastfeeding, how often she is breastfeeding and whether or not the baby is given any other food in addition to breast milk. Women who are fully or partially breastfeeding cannot use all contraceptive methods, although there are many options available to them..$^{4-7}$

Family planning can avert nearly one-third of maternal deaths and $10 \%$ of child mortality, when couples space their pregnancies more than two years apart. ${ }^{8}$ Short intervals between births are linked with higher maternal and child mortality and morbidity. ${ }^{9}$ Postpartum family planning (PPFP) is the prevention of unintended and closely spaced pregnancies through the first twelve months following childbirth. ${ }^{8}$ Postpartum women need a range of effective contraceptive methods to be able to prevent an unplanned pregnancy, within a short interval. ${ }^{819}$ In developing countries, the contraceptive prevalence is low. Women have unregulated fertility and thus unwanted pregnancies, leading to need for abortions with its subsequent ill effects and health of the women. There are many socio-cultural factors that influence the contraceptive utilization. Government is trying its best to promote family planning in India since its first five-year plan.

In India, $65 \%$ of women in the first year postpartum have an unmet need for family planning. Only $26 \%$ of women are using any method of family planning during the first year postpartum. $8 \%$ of the women desire to have another child within the next 2 years after giving birth and are vulnerable to the risks of early pregnancy. ${ }^{10}$ Approximately $27 \%$ of births in India occur in less than 24 months after a previous birth. Another $34 \%$ of births occur between 24 and 35 months. $61 \%$ of births in India occur at intervals that are shorter than the recommended birth-to-birth interval of approximately 36 months. ${ }^{10}$ Aim of the present study was to find out the choice of postpartum contraception among the antenatal women and determine the factors influencing their choices.

\section{METHODS}

A prospective cross-sectional study was Obstetrics undertaken at antenatal Gynaecology clinic of department of obstetrics and gynecology of Pravara Rural Hospital, Loni, Ahmednagar, Maharashtra, India for a period of six months from January 2019 to June 2019.

Pravara rural hospital is located in rural area that caters to large population of the district and the neighboring districts. Approximately 10,000 deliveries take place every year in this hospital. Approximately 4500 antenatal women report to antenatal clinic every month. Average of 30-40 new antenatal women get registered every day in the hospital. Women are called for the check up as per standard protocol of the antenatal clinic. Six-hundred women in third trimester of pregnancy were individually interviewed, while they were waiting for their turn for consultation in the antenatal clinic, about the choice of their contraception during postpartum period using prevalidated and pre-tested short questionnaire. Preliminary data related to individual woman related to her age, education, occupation, religion, parity, number of living children was collected for finding out possible association with the choice of the contraception. Their responses were noted and analysed for deriving conclusion. Privacy and confidentiality were guaranteed to the respondents. Verbal consent was obtained before interview. Women were given educational pamphlets about various methods of contraception after the interview. Interview was conducted by female interviewer so as to get good compliance.

\section{RESULTS}

Six-hundred pregnant women were interviewed during six months period in the ANC clinic. Average time required for the individual interview was less than 5 minutes. Overall, there was positive response from the women. It was observed that $42 \%$ of the pregnant women were below 20 years of age and additional 54\% were between 20-30 years of age (Table 1).

Table 1: Distribution of respondents as per age.

\begin{tabular}{|lll|}
\hline Age group in years & No. of cases & Percentage \\
\hline$\leq 20$ & 252 & $42.00 \%$ \\
\hline $21-25$ & 183 & $30.50 \%$ \\
\hline $26-30$ & 144 & $24.00 \%$ \\
\hline$\geq 30$ & 21 & $3.50 \%$ \\
\hline
\end{tabular}

Table 2: Distribution of respondents as per gravidity.

\begin{tabular}{|lll|}
\hline Gravida & No. of cases & Percentage \\
\hline 1 & 306 & $51.00 \%$ \\
\hline 2 & 226 & $37.66 \%$ \\
\hline 3 & 56 & $9.33 \%$ \\
\hline 4 and above & 12 & $2.00 \%$ \\
\hline
\end{tabular}

Table 3: Distribution of respondents as per number of living children.

\begin{tabular}{|lll|}
\hline $\begin{array}{l}\text { Number of living } \\
\text { children }\end{array}$ & $\begin{array}{l}\text { No. of cases } \\
(\mathbf{n}=\mathbf{2 7 4})\end{array}$ & Percentage \\
\hline 1 & 212 & $77.37 \%$ \\
\hline 2 & 52 & $18.97 \%$ \\
\hline 3 and above & 10 & $3.64 \%$ \\
\hline
\end{tabular}

There were $51 \%$ women, who were primi-gravida and remaining were multi-gravida. Among multi-gravida, majority were second gravidas (78\%). Only $2 \%$ women were pregnant for $4^{\text {th }}$ time or more (Table 2). Among multi-gravid women, $77 \%$ had one child, $19 \%$ had two and 4 percent had three or more children (Table 3). It was observed that $44 \%$ of women had education up to tenth 
class, $27 \%$ had up to intermediate level and $26 \%$ women were completed either graduation or post-graduation (Table 4). Sixty three percent women belonged to middle socio-economic class, $27 \%$ to middle class and remaining $9 \%$ to upper class as per modified Kuppuswami classification (Table 5).

Table 4: Distribution of respondents as per educational status.

\begin{tabular}{|lll|}
\hline Education & No. of cases & Percentage \\
\hline No education-Illiterate & 22 & $3.66 \%$ \\
\hline Primary school & 12 & $2.00 \%$ \\
\hline Middle school & 30 & $5.00 \%$ \\
\hline High school & 220 & $36.66 \%$ \\
\hline Intermediate & 162 & $27.00 \%$ \\
\hline $\begin{array}{l}\text { Graduation or post- } \\
\text { graduation }\end{array}$ & 116 & $19.33 \%$ \\
\hline Profession or honours & 38 & $6.33 \%$ \\
\hline
\end{tabular}

Table 5: Distribution of respondents as per socio economic class-(Modified Kuppuswami classification).

\begin{tabular}{|lll|}
\hline Socio economic class & No. of cases & Percentage \\
\hline Upper (I) & 56 & $9.33 \%$ \\
\hline Upper middle (II) & 254 & $42.33 \%$ \\
\hline Lower middle (III) & 126 & $21.00 \%$ \\
\hline Upper lower (IV) & 124 & $20.66 \%$ \\
\hline Lower (V) & 40 & $6.66 \%$ \\
\hline
\end{tabular}

Among the respondents, majority (67\%) were involved in farming/agriculture work or clerical office work or shop owners, $12 \%$ were involved in professional/service job, mainly as teachers in schools and colleges, security service, telephone operators, bank employee or having some family business. There were either skilled or semiskilled workers $(14 \%)$ or unskilled workers, working either on daily wedges or as domestic help etc., (Table 6).

\section{Table 6: Distribution of respondents as per occupation.}

\begin{tabular}{|lll|}
\hline Socio economic class & $\begin{array}{l}\text { No. of } \\
\text { cases }\end{array}$ & Percentage \\
\hline Unskilled worker & 38 & $6.33 \%$ \\
\hline Semiskilled worker & 54 & $9.00 \%$ \\
\hline Skilled worker & 32 & $5.33 \%$ \\
\hline Clerical, shop owner, farmer & 402 & $67.00 \%$ \\
\hline Semi-profession/profession & 74 & $12.33 \%$ \\
\hline
\end{tabular}

In third trimester, pregnant women were interviewed by social worker regarding their choice of contraception after the present pregnancy. Thirty percent of the total six hundred women, chose permanent sterilization operation ie tubectomy as their choice of contraception. They were mostly multigravida having either one or two living children. Majority of these women were planning for immediate postpartum sterilization operation. Ten percent women opted for barrier contraception, nine percent opted for intrauterine contraceptive device, either PPIUCD or interval IUCD and eight percent opted for oral contraceptive pills, either Mala N or Mala D. Six percent women opted for lactational amenorrhoea method (LAM) and eight percent opted for safe period method or calendar method. Seventeen percent of the women did not respond to the question and mostly were shy to answer due to socio cultural factors. It is likely that some of these couples are practising either abstinence or withdrawal method. Ten percent of the women were confused and were unable to decide about the method. Choice for injectable contraceptive "Antara" and oral non hormonal contraception "Saheli" was chosen by less than two percent women for each of these methods (Table 7).

Table 7: Distribution of respondents as per-choice of postpartum contraception.

\begin{tabular}{|lll|}
\hline Choice of contraception & $\begin{array}{l}\text { Number of } \\
\text { respondents } \\
(\mathbf{n = 6 0 0})\end{array}$ & Percentage \\
\hline Male condom & 57 & $9.50 \%$ \\
\hline Mala D/Mala N & 45 & $7.50 \%$ \\
\hline $\begin{array}{l}\text { Interval copper T } \\
\text { (375/380A) }\end{array}$ & 26 & $4.33 \%$ \\
\hline PPIUCD & 28 & $4.66 \%$ \\
\hline Saheli (centchroman) & 10 & $1.66 \%$ \\
\hline $\begin{array}{l}\text { Antara (long acting } \\
\text { injectable progesterone) }\end{array}$ & 12 & $2.00 \%$ \\
\hline Postpartum tubal ligation & 152 & $25.33 \%$ \\
\hline Interval tubal ligation & 26 & $4.33 \%$ \\
\hline Vasectomy & 0 & $0.00 \%$ \\
\hline $\begin{array}{l}\text { Lactational amenorrhoea } \\
\text { method (LAM) }\end{array}$ & 38 & $6.33 \%$ \\
\hline $\begin{array}{l}\text { Calendar method /safe } \\
\text { period method }\end{array}$ & 45 & $7.50 \%$ \\
\hline $\begin{array}{l}\text { Unable to decide } \\
\text { /confused }\end{array}$ & 60 & $10.00 \%$ \\
\hline No response /shy & 101 & $16.83 \%$ \\
\hline
\end{tabular}

\section{DISCUSSION}

The present study revealed that women who had completed their family often opt for permanent method of contraception in the form of tubectomy operation. Majority of women plan to undergo sterilization operation immediately after normal delivery during same hospital stay or during caesarean section. Tubal ligation is a permanent contraceptive method in which a woman's fallopian tubes are tied off (ligated). Once the tubes have been tied, pregnancy is prevented as eggs are no longer released into the fallopian tubes where they can be fertilized. Tubal ligation is a surgical procedure requiring anesthesia, however women who are breastfeeding can still safely undergo the surgery.

Many women decide the contraceptive choice after the delivery, depending on the sex of the newborn baby. This 
is specifically true, when they desire for a male baby and get the same. Many women have a common belief that breast feeding provides contraception as they are not menstruating during this period. Many women in rural area stay at their parents' home for few months as a cultural practice, so they are practicing abstinence as husband is away from them. The women who are in some profession or job, they cannot practice breast feeding for long time like six months of more than that, thus they opt for alternative feeding and thus start menstruation and ovulation much earlier than women practicing exclusive breast feeding.

Women who are not breastfeeding can safely use all contraceptive methods. However, women who chose to use combined hormonal contraceptive methods, including contraceptive pills, injections, patches and vaginal rings, should delay use until three weeks after childbirth. In this period the woman's risk of developing blood clots in her veins is increased, and using combined hormonal contraceptives further increases the risk of blood clots. ${ }^{11}$

Women who are breastfeeding can safely use a number of contraceptive methods, including: natural and barrier methods; tubal ligation; intrauterine devices; and progesterone-only hormonal contraceptives. Combined hormonal contraceptives are not recommended for use in breastfeeding women until at least six months after childbirth, as using these methods whilst breastfeeding may interfere with breast milk production and also reduce the quality of breast milk. Lactational amenorrhea is a contraceptive method which capitalizes on the natural contraceptive effect of lactation (breastfeeding). While a woman is lactating, the levels of prolactin, increase significantly. This rise in prolactin suppresses ovulation and in doing so prevents pregnancy. Women who breastfeed exclusively do not usually ovulate for at least 6 months after childbirth and $94 \%$ of women who continue breastfeeding for 12 months after childbirth, do not return to ovulation in this time. ${ }^{11}$

Some couples use withdrawal as a contraceptive method in which intercourse is interrupted to enable the male partner to withdraw his penis from the vagina prior to ejaculation. In doing so, egg and sperm are prevented from meeting and pregnancy is avoided. Withdrawal can be used safely during breastfeeding. While this is one of the least effective methods of contraception, it still provides a high level of protection compared to no contraception at all. Many couples do not reveal about the practice of this method for social and cultural inhibitions and illiteracy.

It was observed from the study that around eight percent of pregnant women chose copper bearing intrauterine devices are contraceptive devices which are inserted into the uterus by a health professional. Half of the respondents opted the choice of immediate postpartum IUCD, whereas remaining half planned to have interval IUCD, which is usually inserted six weeks after normal delivery and twelve weeks after caesarean section. They provide long term contraceptive protection, because while an IUD is in place, the uterus undergoes changes in response to the presence of a foreign body (i.e. the IUD). The changes in the uterus make it more difficult for sperm and eggs to survive and fertilize each other, or to implant into the lining of the uterus and form a pregnancy if fertilization occurs. IUDs are safe for use in the postpartum period and during lactation. Studies have shown that copper IUDs do not affect breast milk production or increase the concentration of copper in the breast milk. An IUD can be inserted as soon as 10 minutes after childbirth. ${ }^{11}$

In the present study, only eight percent of the respondents opted the choice of oral hormonal pills. The World Health Organization recommends that breastfeeding women do not use estrogen-containing hormonal contraceptives for at least six months after childbirth as they reduce the quality of breast milk quality. Previously concerns have also been raised about the possibility that progesterone-only hormonal contraceptive methods may increase the amount of progesterone in breast milk, and that this may be dangerous for the breastfed infant, whose liver and kidneys are too immature to metabolize the progesterone. However, numerous studies of progesterone-only methods have now been conducted, and no evidence that their use causes kidney or liver damage in breastfed infants has been found.

Progesterone only contraceptive methods, as the name suggests, contain progesterone as the only hormone. Like combined hormonal methods, they are highly effective in preventing pregnancy and are most effective when used by breastfeeding women as they add to the natural contraceptive protection of breastfeeding. The World Health Organization recommends the use of progesterone only methods for breastfeeding women who gave birth at least six weeks previously.

In the first six weeks after childbirth breast milk production patterns are still being established and progesterone-only methods are not recommended because they may interfere with breast milk production. ${ }^{11}$

The progesterone-only hormonal methods which can be used safely during lactation and are available in Australia are: progesterone only pill or mini pill; progesterone-only injection (Depo Provera); contraceptive implant (Implanon); levonorgestrel intrauterine system (Mirena).Government of India has made a provision of free availability of injectable progesterone for contraception through its peripheral health system.

Many women are still not aware about its availability and only small percent of literate women are using this method of contraception. In the present study, only 2 percent of the respondents showed their inclination towards use of injectable progesterone as method of postpartum contraception. ${ }^{11}$ 
In the present study, ten percent of the respondents chose condom as method of contraception. Women in India, due to hesitancy for talking openly about condom, might have opted this in less number, but in reality, condoms are being used more often than observed in the present study. Female condom is not freely distributed by the government, so many women are not aware about this contraceptive option. Other barrier methods like cervical cap and diaphragm are not available in India, thus not opted by the respondents. Nonoxynol 9 is available in Indian market as Foam tablets with the trade name of "Today." It is not opted by any of the respondents. Barrier methods are methods which work by creating a barrier that prevents the sperm and egg meeting following ejaculation. They are methods which are applied just before sexual intercourse and therefore only need to be used at times when the woman is sexually active. Effectiveness varies depending on the method, with male and female condoms being the most effective barrier methods and cervical caps being the least effective. Male and female condoms also provide the additional benefit of protecting against sexually transmitted infections (STIs) and are thus particularly suitable for women, who have partners of unknown STI status. Barrier methods can be used safely during lactation and include: male condoms; female condoms; diaphragm (although women must delay until six weeks after childbirth to have the device fitted, when uterine involution has occurred or the uterus has returned to its normal size.

Karla $\mathbf{M}$ in their study on knowledge of contraception among teenage pregnant women revealed that the contraception methods about which the participants reported having the least knowledge were the sponge, the diaphragm, implants, the vaginal ring, and various natural methods. The majority $(90.0 \%)$ of the participants agreed that they would prefer to use postpartum contraception. The contraceptive method of choice for postpartum contraception was the IUD $(40 \%)$, which was followed in terms of preference by OCPs $(17.5 \%)$, the patch $(12.5 \%)$, and Depo-Provera (12.5\%). ${ }^{12}$ Lgwegbe AO et al in their study reported that three hundred and forty $(95.5 \%)$ of the respondents knew about family planning out of which $(260 ; 76.5 \%)$ had ever used a modern method. The male condom $(256 ; 75.3 \%)$ and the natural method (Billings method) $(150 ; 44.1 \%)$ were the commonly known methods. ${ }^{13}$ Olamijulo $\mathrm{J}$ et al in their study reported that $45.0 \%$ women planned to use contraceptives after delivery and the male condom $(55.9 \%)$ was the most preferred method of post-partum contraception. There is no statistical association between age, religion, parity and educational attainment and desire for post-partum contraception. ${ }^{14}$ Obisesan KA reported that the awareness of specific methods was $82.6 \%$ for condoms, $75.7 \%$ for oral contraceptives, $75.5 \%$ for injectable contraceptives, and $65.3 \%$ for IUDs. Current use of family planning methods was low, with $10 \%$ using withdrawal, $8.1 \%$ using oral contraceptives, 5.2\% using IUDs, and $4.7 \%$ using condoms. Perceived constraints to the use of family planning methods included husband's opposition, fear of complications, and perceived insufficient knowledge about family planning methods. Based on these results, it is concluded that there is a knowledge-practice gap concerning family planning methods among married women in Ibadan, which will require improvement in education strategies and better access to services..$^{15}$

It was observed that $27 \%$ respondents either did not like to reply or were unable to respond to the question about their choice of postpartum contraception. This was a large group of women, who are illiterate or less educated, who were unaware about various methods, who depend mainly on their husbands wish of either to use or not use any contraceptive. These women were most vulnerable for unplanned pregnancies, as they were not at all involved in the decision-making regarding contraception. In rural areas, there were various myths around oral contraceptive pills and intrauterine contraceptive devices. Some of these myths include that oral pills cause excess weight gain, it is not good for health of women, it causes infertility, whereas intra uterine device causes cancer, it is a foreign body and it is felt by the male partner and causes trauma during intercourse etc. There is need of lots of counselling by the health workers at village level, so that all queries and myths around these devices can be removed.

The present study revealed that majority of illiterate or less educated women either did not tell about their choice of contraception or chose condom. Educated women gave choice of either oral hormonal pills or intrauterine contraceptives. Same was true regarding occupation of women. Women involved in unskilled or semiskilled work, either did not reply or chose condom, as against women in jobs and in profession, who chose either IUCD or oral pills. Women who had children, chose permanent method of contraception as against primi-gravida, who chose either intrauterine contraceptive device or oral pills or injectable progestogens. Majority of women were not aware about injectable contraceptives and non-hormonal contraceptives made available in government hospitals. Lower and lower middle-class women have problems of access to the family planning services in rural areas; thus, they face the problems of unwanted pregnancies more than women from upper middle and upper class.

\section{CONCLUSION}

In India, many women are still not empowered to choose the method of contraception. Their choice contraception is largely dependent on their male counterparts. Among permanent methods, tubal ligation is most commonly chosen method of permanent contraception, whereas condom and copper $\mathrm{T}$, are among the favoured temporary methods of contraception. Recently, postpartum IUCD is becoming popular choice of contraception. There are still lots of myths around hormonal pills and the intrauterine devices in India, which is affecting its acceptance. Women living in rural area are still not aware about the availability of injectable contraceptives. Female condom, 
progesterone only contraceptives, sub-dermal implants are still not included by government in their family planning programme. Continuous efforts are needed to improve the contraceptive prevalence for population stabilization in India.

Funding: No funding sources

Conflict of interest: None declared

Ethical approval: The study was approved by the Institutional Ethics Committee

\section{REFERENCES}

1. Family planning: A global handbook for providers. World Health Organization; 2007. Available at: https://www.who.int/reproductivehealth/publications /fp-global-handbook/en/. Accessed on $12^{\text {th }}$ March 2020.

2. WHealth benefits of family planning. World Health Organization; $1995 . \quad$ Available at: http://whqlibdoc.who.int/hq/1995/WHO_FHE_FPP_ 95.11.pdf. Accessed on $12^{\text {th }}$ March 2020 .

3. 2002 PRAMS Surveillance Report: Multistate exhibits - Postpartum contraceptive use. Centers for disease control and prevention; 2006.

4. Germano E, Jenning V. New approaches to fertility awareness-based methods: incorporating the standard days and two days methods into practice. J Midwifery Women's Health. 2006;51:471-7.

5. King J. Contraception and lactation. J Midwifery Women's Health. 2007;52(6):614-20.

6. Progesterone-only contraceptive use during lactation and its effects on the neonate. World Health Organization; 2009. Available at: https://www.who.int/reproductivehealth/publications /family_planning/WHO_RHR_09_13/en/. Accessed on $12^{\text {th }}$ March 2020.

7. Contraception: A guide to help you choose. Marie Stopes International Australia; 2007.
8. Cleland J, Bernstein S, Ezeh A, Faundes A, Glasier A, Innis J. Family planning: the unfinished agenda. Lancet. 2006;368:1810-27.

9. Rutstein S. Further evidence of the effects of preceding birth intervals on neonatal, infant, and under-five-years mortality and nutritional status in developing countries: evidence from the demographic and health surveys. DHS Working. Macro International; 2008.

10. Postpartum IUCD reference manual, Family Planning Division, Ministry of Health and Family Welfare, Government of India; 2010.

11. Contraception after childbirth and during breastfeeding. Available at: https://healthengine.com.au/info/contraception-afterchildbirth-and-during-breastfeeding. Accessed on $18^{\text {th }}$ March 2020.

12. Karla M. Knowledge and choices of postpartum contraception among pregnant teens. P R Health Sci J. 2014;33(3):117-21.

13. Igwegbe AO, Ugboaja JO, Monago EN. Knowledge and practice of family planning among antenatal care attendees at Nnewi, south east Nigeria. Niger Postgraduate Med J. 2010 Dec;17(4):287-90.

14. Olamijulo J. Knowledge and practice of contraception among pregnant women attending the antenatal clinic in Lagos University Teaching Hospital. Niger J Med. 2012;21(4):387-93.

15. Obisesan K. Awareness and use of family planning methods among married women in Ibadan, Nigeria East. Afr Med J. 1998;75(3):135-8.

Cite this article as: Bangal VB, Thitame $S$, Somasundaram KV. Choice of postpartum contraception and its socio-demographic and cultural determinants. Int $\mathbf{J}$ Reprod Contracept Obstet Gynecol 2020;9:2866-71. 